\title{
Presumed toxoplasmic central retinal artery occlusion and multifocal retinitis with perivascular sheathing
}

This article was published in the following Dove Press journal:

Clinical Ophthalmology

23 April 2014

Number of times this article has been viewed

\author{
Haruka Arai' \\ Tsutomu Sakai' \\ Kiichiro Okano' \\ Ranko Aoyagi' \\ Ayano Imai \\ Hiroshi Takase ${ }^{2}$ \\ Manabu Mochizuki² \\ Hiroshi Tsuneoka' \\ 'Department of Ophthalmology, Jikei \\ University School of Medicine, Tokyo, \\ Japan; ${ }^{2}$ Department of Ophthalmology \\ and Visual Science, Tokyo Medical and \\ Dental University, Tokyo, Japan
}

Correspondence: Tsutomu Saka Department of Ophthalmology, Jikei University School of Medicine, 3-25-8 Nishishimbashi, Minato-ku,

Tokyo I05-846I, Japan

$\mathrm{Tel}+8 \mid 33433$ IIII ext 358 |

$\mathrm{Fax}+81334331936$

Email tstmski@jikei.ac.jp

\begin{abstract}
Central retinal artery occlusion (CRAO) and multifocal retinitis with perivascular sheathing are rare in ocular toxoplasmosis. We report a case of toxoplasmic CRAO and multifocal retinitis with perivascular sheathing. A healthy 83 -year-old male developed left panuveitis. Funduscopic examination of the left eye showed a swollen optic disc and sheathing of the retinal artery with a dense vitreous haze and a white retinal lesion. Serum anti-toxoplasma antibodies were positive in a latex agglutination assay. Vitrectomy was performed to improve visualization of the retinal lesions and for examination of causative microorganisms. A postoperative fundus examination revealed CRAO with optic disc involvement and multifocal retinitis with perivascular sheathing. Qualitative multiplex polymerase chain reaction detected the Toxoplasma gondii B1 gene in ocular fluid from both the aqueous and vitreous humor. The presumed diagnosis of ocular toxoplasmosis was made and treatment was started with prednisone and acetylspiramycin with subsequent improvement. Two months later, the patient developed active retinochoroiditis in the left eye. After 6 weeks of anti-toxoplasma therapy, the disease involuted. Retinal vascular occlusions and multifocal retinitis with perivascular sheathing are rare in toxoplasmosis. This is the first case report of toxoplasmic CRAO and multifocal retinitis with perivascular sheathing. The diagnosis of ocular toxoplasmosis should be considered in patients with retinal artery occlusions and multifocal retinitis with perivascular sheathing associated with inflammation.
\end{abstract}

Keywords: ocular toxoplasmosis, toxoplasma retinochoroiditis, retinal vascular occlusion, polymerase chain reaction, vitrectomy

\section{Introduction}

Retinochoroiditis is a common intraocular manifestation of ocular toxoplasmosis. ${ }^{1}$ In the last decade, several manifestations of ocular toxoplasmosis have been reported, ${ }^{1-5}$ including optic neuropathy and retinal vascular occlusion. Wong et al reported a rare case of optic disc swelling and hemispherical retinal vein occlusion treated with intravitreal clindamycin. ${ }^{6}$ Herein, we describe the first case of toxoplasmic central retinal artery occlusion (CRAO) with optic disc involvement and multifocal retinitis with perivascular sheathing.

\section{Case report}

The patient was an 83-year-old Japanese man who had been suffering from visual loss and a history of floaters in the left eye from 3 weeks before. He was diagnosed with iritis with mild vitreous haze in the left eye and was initially treated with dexamethasone sodium phosphate eye drops. He was referred to our hospital for increased vitreous haze with the presence of retinal white exudates. He was immunocompetent and had no underlying systemic diseases. 
On presentation, the best-corrected visual acuity (BCVA) was 0.9 OD and 0.2 OS. There was a left relative afferent pupillary defect. The patient had $1+$ cell and $1+$ flare in the anterior chamber and $3+$ cells with trace haze in the vitreous of the left eye. Funduscopic examination of the left eye showed a swollen optic disc and sheathing of the retinal artery with a dense vitreous haze and a white retinal lesion. The right eye appeared normal. Serum anti-toxoplasma antibodies were positive in a latex agglutination assay (1:640) and toxoplasma immunoglobulin (Ig)G antibodies were positive in an enzymelinked immunosorbent assay (ELISA) (176 IU/mL). Other serologic test results, including those for anti-toxoplasma IgM antibodies, angiotensin-converting enzyme, and viral antibodies such as herpes simplex virus, varicella zoster virus, and Cytomegalovirus, were within normal limits. Testing of viral DNA in the anterior chamber gave negative results for herpes simplex virus, varicella zoster virus, Cytomegalovirus, and Epstein-Barr virus.
The patient was initially treated with anti-inflammatory eye drops and oral aspirin (100 mg/day), but vitreous haze progressively worsened within a few days and the BCVA was hand-motion OS. The right eye appeared normal and the BCVA was 0.9 OD. A 25-gauge pars plana vitrectomy was performed to improve visualization of the retinal lesions and for examination of causative microorganisms under local anesthesia. After removal of vitreous haze following direct aspiration to obtain vitreous specimens, a swollen optic disc and a cherry-red spot with sheathing of the central retinal artery were found in the macula, suggesting development of CRAO. In addition, multifocal retinitis with focal periarterial exudates and arterial plaques were observed in the mid-periphery. A postoperative fundus examination revealed characteristic findings (Figure 1A) and fluorescence angiography demonstrated optic disc leakage, poor retinal perfusion, and periarterial plaques (Figure 1B). Optical coherence tomography showed thickening of the inner retina and decreased reflectivity of the normally
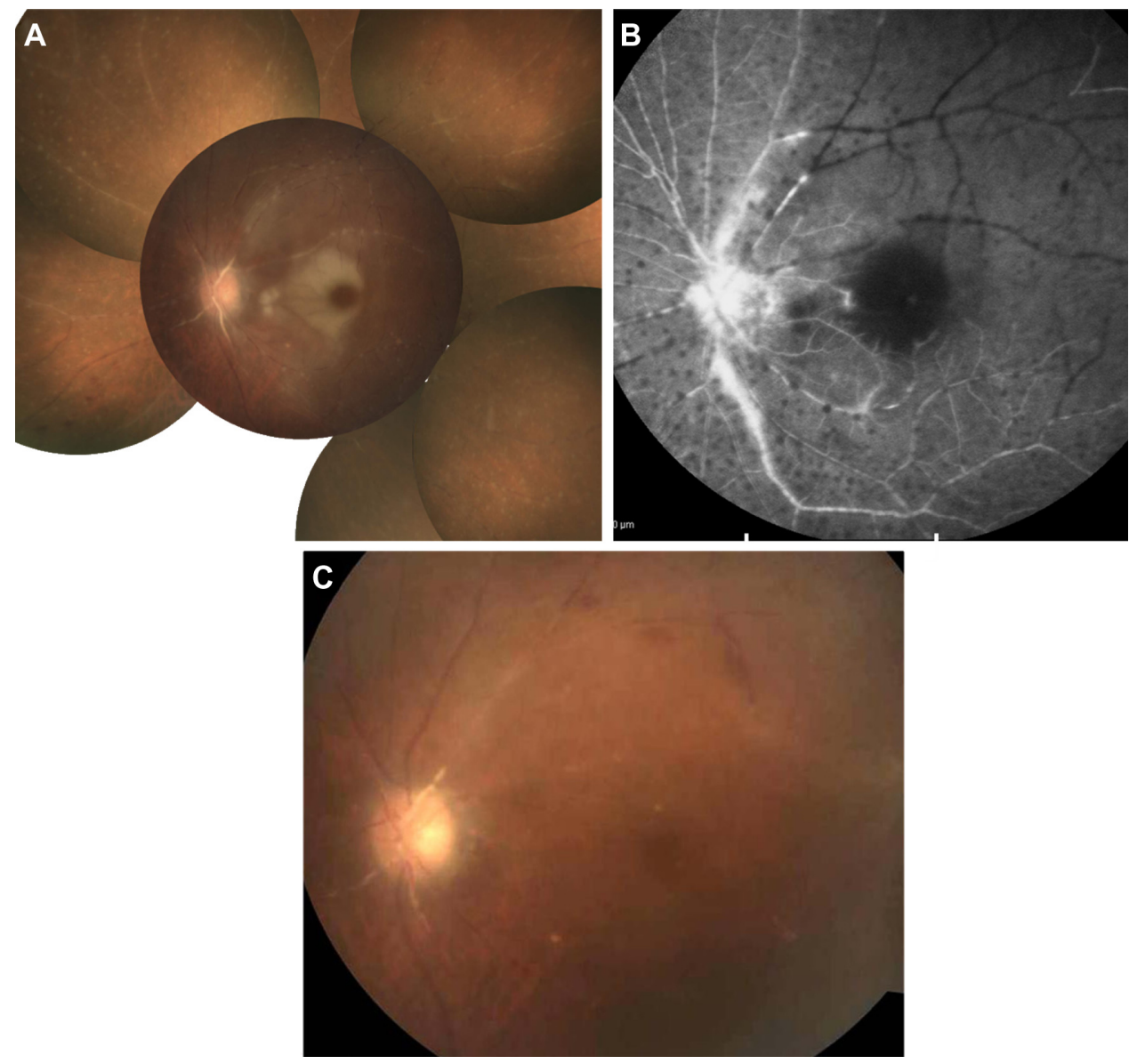

Figure I Fundus photograph and fluorescein angiography after surgery.

Notes: (A) Fundus photograph at 20 hours after surgery showing a cherry-red spot and multifocal retinitis with sheathing of the retinal arteries. (B) Fluorescein angiography at 20 hours after surgery showing evidence of the plaques on the walls of blood vessels, the periarterial exudates, and obstruction to blood flow. (C) Fundus photograph at 2 months after surgery showing disappearance of the cherry-red spot. 
hyperreflective IS/OS junction. The postoperative BCVA was $0.9 \mathrm{OD}$ and $0.1 \mathrm{OS}$.

The results of vitreous cultures were negative and the interleukin-10/interleukin-6 ratio was $<1.0$. Qualitative multiplex polymerase chain reaction (PCR) detected the Toxoplasma gondii B1 gene in ocular fluid from both the aqueous and vitreous humor. Quantitative real-time PCR revealed high copy numbers of $T$. gondii DNA of $4.0 \times 10^{5}$ and $5.3 \times 10^{5} \mathrm{copies} / \mathrm{mL}$ in the aqueous and vitreous humor, respectively. These findings led to diagnosis of presumed toxoplasmic CRAO with optic disc involvement and multifocal retinitis with perivascular sheathing. The patient was treated with oral acetylspiramycin $(1,200 \mathrm{mg}$ /day) and oral prednisone $(20 \mathrm{mg} /$ day). Two months after surgery, the lesion had slowly regressed (Figure 1C).

Two months later, the patient noticed an increase in floaters in the left eye. An examination showed that there was a large area of active retinochoroiditis that seemed to point toward the macula (Figure 2A). Fluorescence angiography of the active lesion demonstrated early blockage with subsequent leakage from the lesion (Figure 2B and C). We considered recurrent ocular toxoplasmosis as a strong possibility and oral clindamycin (600 mg/day) was added on this basis. The patient was followed up weekly and, after 6 weeks of therapy, the disease involuted.

\section{Discussion}

We here present a first report of toxoplasmic CRAO and multifocal retinitis with perivascular sheathing and otherwise atypical presentation. The difficulty in making an early diagnosis in a case of ocular toxoplasmosis is compounded by some patients with ocular involvement having no history of toxoplasmic infection or typical manifestations of ocular toxoplasmosis.

Ocular manifestations associated with toxoplasmosis may be caused by an active infection or an immunologic reaction in the absence of any infectious agent. ${ }^{1}$ Our case presented with CRAO with optic disc involvement and multifocal retinitis with perivascular sheathing as a primary manifestation, in contrast to cases with this condition
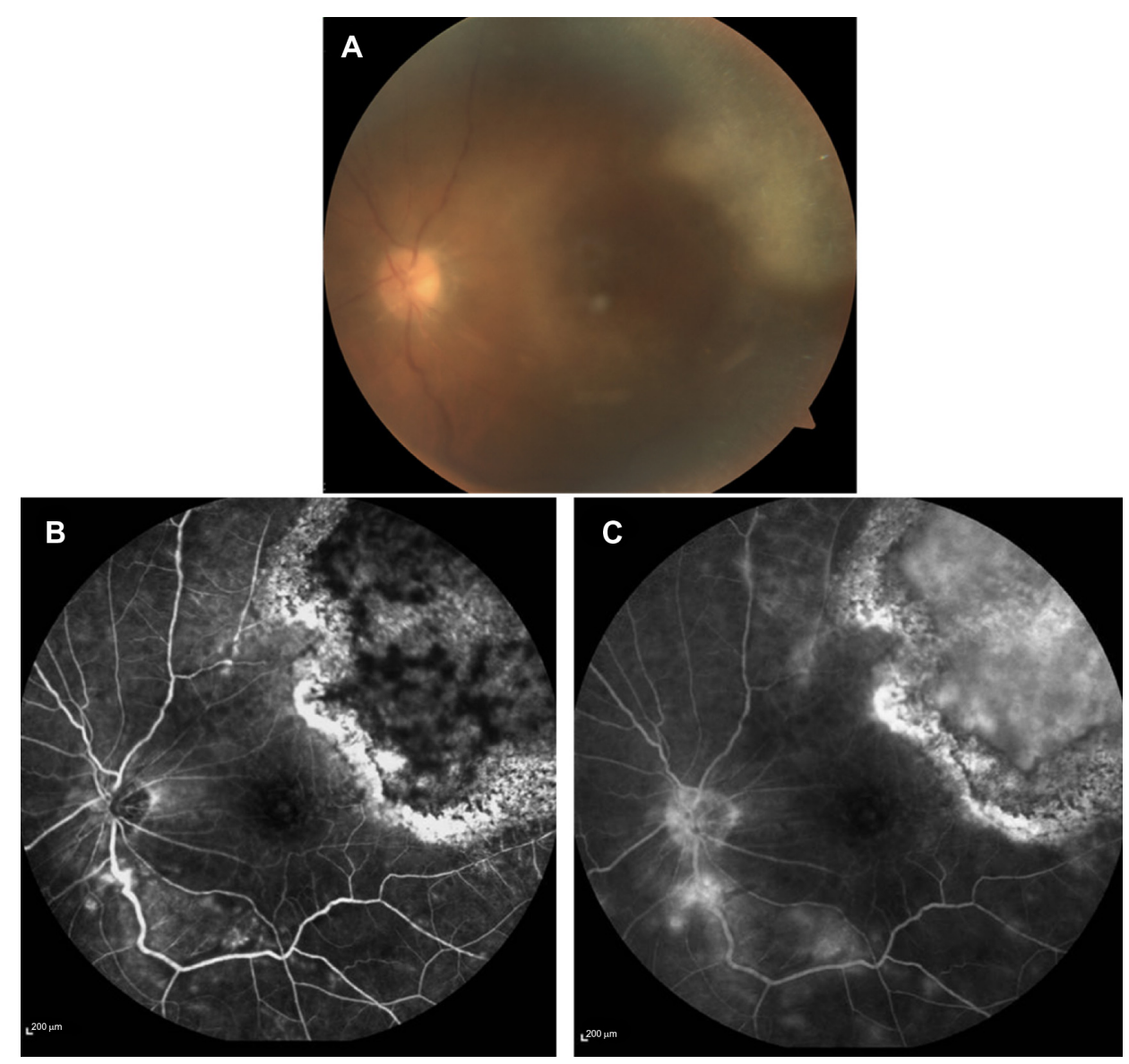

Figure 2 Fundus photograph and fluorescein angiography at 3 months after surgery.

Notes: (A) Fundus photograph showing a large area of active retinochoroiditis that seemed to point toward the macula. (B) An early-phase image showing early blockage of active lesion. (C) A late-phase image showing subsequent leakage of the lesion. 
diagnosed as a secondary manifestation to preexisting retinochoroiditis. Possibly, there may be a difference in the immunological background between the two presentations of ocular toxoplasmosis, although we did not evaluate the patient's immune status.

PCR is increasingly used for diagnostic purposes and has become a mainstay for diagnosis. Rothova et al noted that DNA from T. gondii was more frequently found intraocularly in cases of recently acquired disease compared with recurrent ocular toxoplasmosis (37\% versus $4 \%) .{ }^{7}$ Mahalakshmi et al ${ }^{8}$ suggested that use of PCR was preferable because of the small amount of specimen needed, the rapidity of the test, and the cost. Acute ocular toxoplasmosis may occur most often in patients with serologic evidence of infection with positive IgM antibodies, but diagnosis of this disease by serologic means alone may not always be reliable. ${ }^{9}$ Although paired samples of aqueous humor and serum were not analyzed in parallel in this case, we believe that the high copy numbers of $T$. gondii DNA in the ocular fluid might have been associated with development of CRAO and multifocal retinitis with perivascular sheathing. Thus, PCR analysis using the aqueous and vitreous humor may be particularly helpful for diagnosis of ocular toxoplasmosis with atypical lesions. ${ }^{1,10-12}$ The use of real-time PCR confirms the specificity and clinical meaning of a positive result in our case. Thus, we were able, despite the absence of ELISA data using ocular fluids, in our case, to corroborate the diagnosis of presumed toxoplasmic CRAO and diffuse retinal vasculitis by the combined positive results of serum ELISA and quantitative real-time PCR using ocular fluids. This was further confirmed by the clinical course with occurrence of a large retinochoroiditis lesion in the partner eye. This case highlights how a high index of suspicion is required to diagnose ocular toxoplasmosis.

Clinical Ophthalmology

\section{Publish your work in this journal}

Clinical Ophthalmology is an international, peer-reviewed journal covering all subspecialties within ophthalmology. Key topics include: Optometry; Visual science; Pharmacology and drug therapy in eye diseases; Basic Sciences; Primary and Secondary eye care; Patient Safety and Quality of Care Improvements. This journal is indexed on Submit your manuscript here: http://www.dovepress.com/clinical-ophthalmology-journal

\section{Disclosure}

The authors report no conflicts of interest in this work.

\section{References}

1. Butler NJ, Furtado JM, Winthrop KL, Smith JR. Ocular toxoplasmosis II: clinical features, pathology and management. Clin Experiment Ophthalmol. 2013;41:95-108.

2. Küçükerdönmez C, Akova YA, Yilmaz G. Ocular toxoplasmosis presenting as neuroretinitis: report of two cases. Ocul Immunol Inflamm. 2002;10:229-234.

3. Smith JR, Cunningham ET Jr. Atypical presentations of ocular toxoplasmosis. Curr Opin Ophthalmol. 2002;13:387-392.

4. Perrotta S, Nobili B, Grassia C, Sebastiani A, Parmeggiani F, Costagliola C. Bilateral neuroretinitis in a 6-year-old boy with acquired toxoplasmosis. Arch Ophthalmol. 2003;121:1493-1496.

5. Lee MW, Fong KS, Hsu LY, Lim WK. Optic nerve toxoplasmosis and orbital inflammation as initial presentation of AIDS. Graefes Arch Clin Exp Ophthalmol. 2006;244:1542-1544.

6. Wong R, dell'Omo R, Marino M, Hussein B, Okhravi N, Pavesio CE. Toxoplasma gondii: an atypical presentation of toxoplasma as optic disc swelling and hemispherical retinal vein occlusion treated with intravitreal clindamycin. Int Ophthalmol. 2009;29:195-198.

7. Rothova A, de Boer JH, Ten Dam-van Loon NH, et al. Usefulness of aqueous humor analysis for the diagnosis of posterior uveitis. Ophthalmology. 2008;115:306-311.

8. Mahalakshmi B, Therese KL, Madhavan HN, Biswas J. Diagnostic value of specific local antibody production and nucleic acid amplification technique-nested polymerase chain reaction (nPCR) in clinically suspected ocular toxoplasmosis. Ocul Immunol Inflamm. 2006;14:105-112.

9. Rothova A, van Knapen F, Baarsma GS, Kruit PJ, Loewer-Sieger DH, Kijlstra A. Serology in ocular toxoplasmosis. Br J Ophthalmol. 1986;70:615-622.

10. Garweg JG, de Groot-Mijnes JD, Montoya JG. Diagnostic approach to ocular toxoplasmosis. Ocul Immunol Inflamm. 2011;19:255-261.

11. Sugita S, Ogawa M, Inoue S, Shimizu N, Mochizuki M. Diagnosis of ocular toxoplasmosis by two polymerase chain reaction (PCR) examinations: qualitative multiplex and quantitative real-time. Jpn J Ophthalmol. 2011;55:495-501.

12. Sugita S, Ogawa M, Shimizu N, et al. Use of a comprehensive polymerase chain reaction system for diagnosis of ocular infectious diseases. Ophthalmology. 2013;120:1761-1768.

\section{Dovepress}

PubMed Central and CAS, and is the official journal of The Society of Clinical Ophthalmology (SCO). The manuscript management system is completely online and includes a very quick and fair peer-review system, which is all easy to use. Visit http://www.dovepress.com/ testimonials.php to read real quotes from published authors. 